\title{
Bu-Shen-Ning-Xin Decoction ameliorated the osteoporotic phenotype of ovariectomized mice without affecting the serum estrogen concentration or uterus
}

\author{
This article was published in the following Dove Press journal: \\ Drug Design, Development and Therapy \\ 31 August 2015 \\ Number of times this article has been viewed
}

\author{
Ling Wang ${ }^{1,2, *}$ \\ Xue-Min Qiu ${ }^{1,2, *}$ \\ Yu-Yan Guil,2 \\ Ying-Ping $X u^{1,2}$ \\ Hans-Jürgen Gober ${ }^{3}$ \\ Da-Jin $\mathrm{Li}^{\prime}$
}

'Laboratory for Reproductive Immunology, Hospital and Institute of Obstetrics and Gynecology, IBS, Fudan University Shanghai Medical College, ${ }^{2}$ Shanghai Key Laboratory of Female Reproductive Endocrine Related Diseases, Shanghai, People's Republic of China; ${ }^{3}$ Department of Pharmacy, Wagner Jauregg Hospital and Children's Hospital, Linz, Austria

*These authors contributed equally to this work

\begin{abstract}
Introduction: Bu-Shen-Ning-Xin Decoction (BSNXD), a traditional Chinese medicinal composition, has been used as a remedy for postmenopausal osteoporosis, but its effects on bone metabolism and the uterus have not been reported.

Purpose: We aimed to determine the respective effects of BSNXD on the bones and the uterus of ovariectomized (OVX) mice to evaluate the efficacy and safety of this herbal formula.

Materials and methods: Postmenopausal osteoporosis animal models that were generated by ovariectomy were treated with BSNXD. Dual-energy X-ray absorptiometry was performed to analyze the bone mineral density, and histomorphometric analysis was performed to measure the parameters related to bone metabolism. Calcein labeling was performed to detect bone formation. The uteruses from the mice were weighed, and the histomorphometry was analyzed. Drug-derived serum was prepared to assess the $17-\beta$-estradiol concentration via enzyme immunoassay.

Results: BSNXD administration ameliorated the osteoporotic phenotype of OVX mice, as evidenced by an increase in the bone mineral density and bone volume; these effects could not be abolished by the administration of the aromatase inhibitor letrozole. Moreover, BSNXD had no effect on the serum estrogen concentration or uterus.
\end{abstract}

Conclusion: These results suggest that BSNXD has ameliorating effects on bone loss due to estrogen deprivation without affecting the peripheral blood estrogen concentration or the uterus in OVX mice.

Keywords: traditional Chinese medicine, postmenopausal osteoporosis, OVX, bone phenotype, estrogen

\section{Introduction}

Postmenopausal osteoporosis (PMO) is a major health concern worldwide, especially in countries with an aging population. Estrogen deficiency disrupts the balance between osteoblastic bone formation and osteoclastic bone resorption in favor of increased resorption, leading to bone loss.

Bisphosphonates are considered first-line therapy for PMO because of their efficacy across multiple skeletal sites; however, there are potential short- and long-term safety concerns. Selective estrogen receptor modulators are considered for younger postmenopausal women who are at a greater risk of vertebral than hip fractures. The marked benefits of raloxifene on the reduction in vertebral fracture risk are partially counterbalanced by the lack of an effect on non-vertebral fracture risk and an increased risk of venous thromboembolism and stroke. Estrogen replacement therapy in postmenopausal women increases the estrogen levels and prevents postmenopausal
Correspondence: Da-Jin Li Laboratory for Reproductive Immunology, Hospital \& Institute of Obstetrics and Gynecology, IBS, Fudan University Shanghai Medical College, Shanghai 2000II, People's Republic of China Tel +86 2l 6345733 I

Email djli@shmu.edu.cn 
bone loss, but there is still controversy over its safety. The Women's Health Initiative Study has demonstrated that longterm estrogen replacement causes an unacceptable increase in the risk of heart attack, stroke, and breast and uterine cancer. ${ }^{1}$ Recently, a "critical time window" has been proposed in which estrogen use early in the menopause transition may be beneficial, while estrogen use later in life could lead to increased health risks. ${ }^{2}$ Besides, hormone replacement therapy should not be prescribed for osteoporosis in women who do not experience menopausal symptoms. Denosumab is a full human monoclonal antibody to receptor activator for nuclear factor- $\mathrm{KB}$ ligand (RANKL), and is considered in the treatment of women who have a high fracture risk or who have failed other osteoporosis therapies. It will be important to explore newer agents that can be used for individualized therapy to optimize the clinical outcomes in patients with osteoporosis. ${ }^{3,4}$ As a result, other potential therapeutic interventions, including traditional Chinese medicine (TCM), have been examined.

TCMs have been used in the People's Republic of China and other Asian countries for over 5,000 years to prevent and treat a variety of diseases. Unlike target-oriented modern medicine, TCM uses a holistic and synergistic approach to restore the balance of Yin-Yang of body energy so that normal function and homeostasis are restored in the body. ${ }^{5}$ Herbal TCMs often consist of a combination of individual herbs to form specific formulae that are aimed at increasing the therapeutic efficacy and reducing adverse effects. ${ }^{6}$ According to the main hypothesis of TCM, multiple active phytochemical components in the TCM formulae may simultaneously target multiple molecules/pathways and thus potentially achieve a superior effect compared to single compounds alone. ${ }^{7}$

Many plant-derived natural products have been used in traditional medicine to treat PMO. Bu-Shen-Ning-Xin Decoction (BSNXD), a complicated cocktail therapy derived from TCM Er-Xian Decoction and Zhi Bai Dihuang pill, has good therapeutic effects on perimenopausal syndrome, ${ }^{8}$ and it has been used for preventing and treating menopause-related disorders, including osteoporosis. ${ }^{9}$ BSNXD, a TCM remedy, contains Drying Rehmannia Root, Common Anemarrhena Rhizome, Bark of Chinese Corktree, Barbary Wolfberry Fruit, Chinese Dodder Seed, Shorthorned Epimedium Herb, Spina Date Seed, and Oriental Waterplantain Rhizome (Table 1). The BSNXD involves many key constituent

Table I The composition and preparation of the herbal formula BSNXD

\begin{tabular}{|c|c|c|c|}
\hline Crude herbs & Latin names & Content & Main components \\
\hline \multirow[t]{3}{*}{ Drying Rehmannia Root } & Radix Rehmanniae Exsiccata & $15 \mathrm{~g}$ & Catalpol \\
\hline & & & Acteoside \\
\hline & & & Apigenin \\
\hline \multirow[t]{3}{*}{ Common Anemarrhena Rhizome } & Anemarrhena asphodeloides Bunge & $15 \mathrm{~g}$ & Sarsasapogein \\
\hline & & & Timosaponin \\
\hline & & & Markogein \\
\hline \multirow[t]{3}{*}{ Bark of Chinese Corktree } & Phellodendron amurense Rupr. & $9 \mathrm{~g}$ & Berberine \\
\hline & & & Phellodendrine \\
\hline & & & Jatrorrhizine \\
\hline \multirow[t]{3}{*}{ Barbary Wolfberry Fruit } & Fructus Lycii barbari & $15 \mathrm{~g}$ & Lycium barbarum polysaccharides \\
\hline & & & $\beta$-Carotene \\
\hline & & & Quercetin \\
\hline \multirow[t]{3}{*}{ Chinese Dodder Seed } & Cuscuta chinensis & $12 \mathrm{~g}$ & Quercetin \\
\hline & & & Kaempferol \\
\hline & & & Hyperoside \\
\hline \multirow[t]{3}{*}{ Shorthorned Epimedium Herb } & Epimedium brevicornu Maxim & $12 \mathrm{~g}$ & Icariin \\
\hline & & & Icariin I \\
\hline & & & Icariin II \\
\hline \multirow[t]{3}{*}{ Spina Date Seed } & Ziziphus jujuba Mill. var. spinosa & $9 \mathrm{~g}$ & Jujuboside $A$ \\
\hline & & & Jujuboside AI \\
\hline & & & Jujuboside C \\
\hline \multirow[t]{3}{*}{ Oriental Waterplantain Rhizome } & Alisma plantago-aquatica Linn. & $12 \mathrm{~g}$ & Alisol A \\
\hline & & & Alisol B \\
\hline & & & Alisol C 23 acetate \\
\hline
\end{tabular}

Notes: Based on the traditional method, the crude herbs mentioned above ( 15 times) were mixed, immersed in deionized water (ten times the herbs' total weight), and then boiled at $90^{\circ} \mathrm{C}$ for 60 minutes for the first decoction. An aqueous extract was made by boiling the herbs three times to make a decoction. The three extracts were combined and concentrated by rotary evaporator (Model NI000, Eyela, Tokyo, Japan). The yield of the BSNXD extract was $742.5 \mathrm{~mL}$ with $2 \mathrm{~g} / \mathrm{mL}$ (w/v) total raw herbs. Abbreviation: BSNXD, Bu-Shen-Ning-Xin Decoction. 
compounds just like glucoside, flavonoid, and saponins. Sixteen components have been identified in BSNXD fingerprint analysis as acteoside, apigenin, sarsasapogein, imosaponin A3, berberine, jatrorrhizine, quercetin, icarlin, and more (Figure 1). Some of these compounds have been reported to have the similar action on osteoporosis. Apigenin can inhibit osteoblastogenesis and prevents bone loss in ovariectomized (OVX) mice. ${ }^{10}$ Also, quercetin can upregulate the antioxidant response in osteoblasts (OBs). ${ }^{11} \mathrm{BSNXD}$ has been used for decades to treat and prevent menopause-related disorders and diseases of aging, ${ }^{8}$ including osteoporosis. While BSNXD has a beneficial effect on skeletal mass, ${ }^{9}$ the cellular and molecular mechanisms mediating this action are not yet fully understood. In a previous study, we collected pharmacological serum from OVX mice treated with BSNXD and found that BSNXD pharmacological serum both promoted the proliferation and inhibited the apoptosis of murine OBs through activating MAPK signaling pathways via phosphorylation of ERK1/2. ${ }^{9}$

To further explore the effects of BSNXD on PMO, we used an animal model of ovariectomy in female mice to deplete their ovarian hormones. ${ }^{12,13}$ The aim of the present study was to observe the respective effects of BSNXD on the bone phenotype, peripheral blood estrogen concentration,

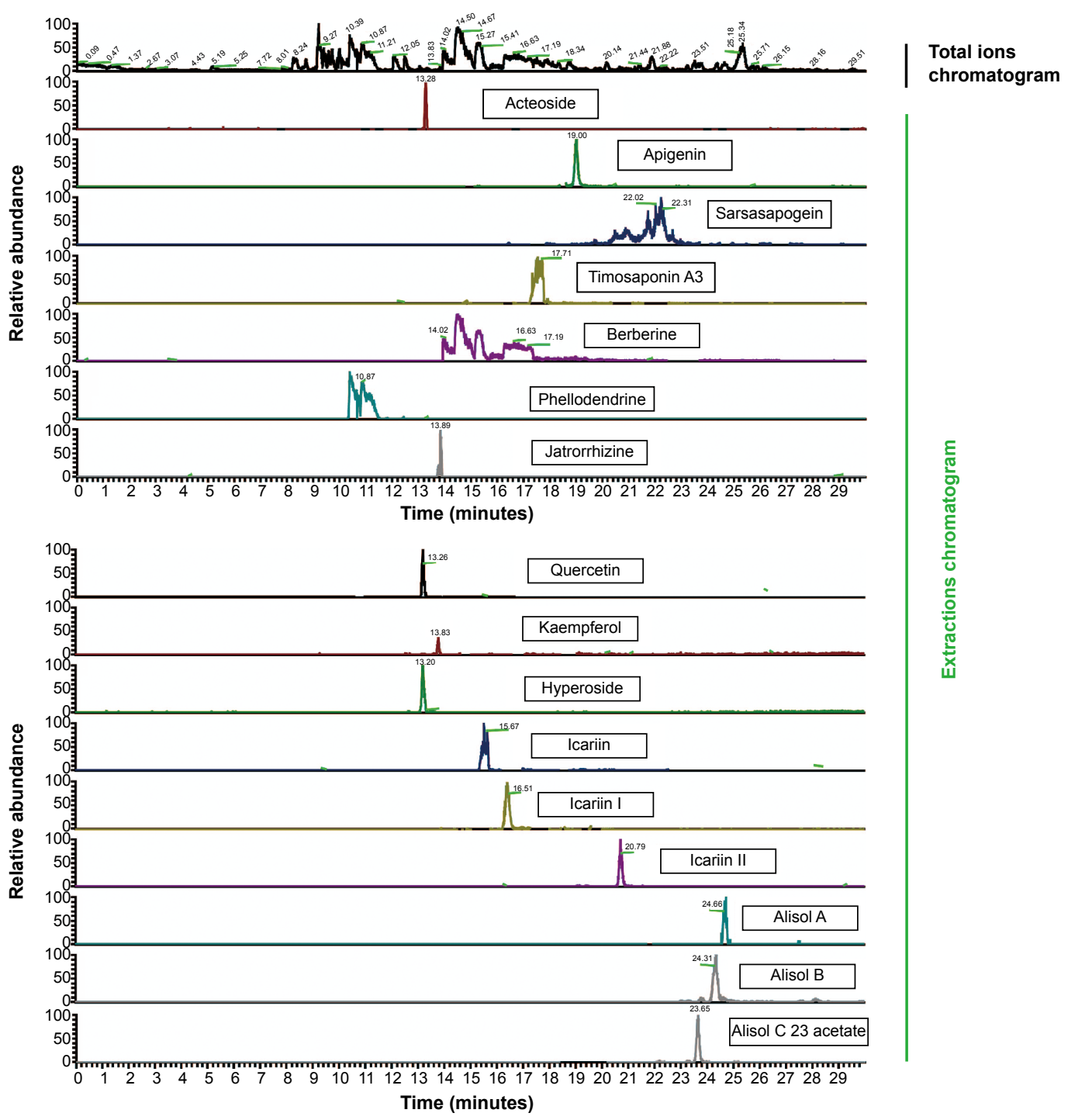

Figure I Identification of the key components in BSNXD.

Notes: The BSNXD extracts were centrifuged at 20,000 $\mathrm{g}$ for 5 minutes, and the supernatant was transferred to another new tube. The supernatant was dried completely with speed vacuum. The sample was dissolved in I mL of solvent $\mathrm{A}\left(0.1 \%\right.$ formic acid, $2 \%$ acetonitrile, $\left.98 \% \mathrm{H}_{2} \mathrm{O}\right)$. Four microliters of samples was then injected into a manually packed reversed phase CI 8 column ( $170 \mathrm{~mm} \times 79 \mu \mathrm{m}, 3 \mu \mathrm{m}$ particle size, Dikma) coupled to Easy-nLC (Thermo Fisher Scientific), and was eluted from $0 \%$ to $100 \%$ solvent $B$ $\left(0.1 \%\right.$ formic acid in $90 \%$ acetonitrile and $10 \% \mathrm{H}_{2} \mathrm{O}$ ) in solvent $\mathrm{A}$ with a 30 -minute gradient at a flow rate of $300 \mathrm{~nL} / \mathrm{min}$. The fractions were analyzed by using Orbitrap Fusion mass spectrometer at a resolution of 120,000 at $\mathrm{m} / \mathrm{z}=200$. The compound peaks were determined according to the monoisotopic peak of compounds with an error of 10 ppm. Abbreviation: BSNXD, Bu-Shen-Ning-Xin Decoction. 
and uterus in OVX mice and identify the efficacy and safety of this herbal formula.

\section{Materials and methods Chemicals}

Formic acid, acetonitrile, saline, 17- $\beta$-estradiol, letrozole, calcein, hematoxylin and eosin, a von Kossa staining kit, and a tartrate-resistant acid phosphatase (TRAP) activity assessment kit were purchased from Sigma-Aldrich (St Louis, MO, USA). The toluidine blue staining solution was purchased from Leagene Inc. (Beijing, People's Republic of China). The estradiol (E2) enzyme immunoassay (EIA) kit was purchased from BioCheck Inc. (Burlingame, CA, USA).

\section{Preparation of BSNXD extracts and fingerprint analysis}

Herbal formula BSNXD consists of eight crude herbs that are prepared as indicated in Table 1. The rule of compositions is part of traditional Chinese medicinal theory, and the compositions are derived according to our clinical experience. BSNXD was obtained from the pharmacy of the Hospital of Obstetrics and Gynecology, Fudan University, Shanghai, People's Republic of China. The products were manufactured under good manufacturing practice conditions at the Institute of Obstetrics and Gynecology, Fudan University Shanghai Medical College according to a modified version of the protocol described in Chinese Pharmacopoeia 2005. ${ }^{14}$ Crude water extracts were prepared from powdered BSNXD. ${ }^{8,9}$

To analyze the fingerprint, the BSNXD extracts were centrifuged at $20,000 \times g$ for 5 minutes, and the supernatant was transferred to another new tube. The supernatant was dried completely with speed vacuum. The sample was dissolved in $1 \mathrm{~mL}$ of solvent A (0.1\% formic acid, $2 \%$ acetonitrile, $98 \% \mathrm{H}_{2} \mathrm{O}$ ). Four microliters of samples was then injected into a manually packed reversed phase C18 column (170 mm ×79 $\mathrm{m}, 3 \mu \mathrm{m}$ particle size; Dikma, Beijing, People's Republic of China) coupled to Easy-nLC (Thermo Fisher Scientific, Waltham, MA, USA), and was eluted from $0 \%$ to $100 \%$ in solvent B $\left(0.1 \%\right.$ formic acid in $90 \%$ acetonitrile and $\left.10 \% \mathrm{H}_{2} \mathrm{O}\right)$ in solvent A with a 30-minute gradient at a flow rate of $300 \mathrm{~nL} / \mathrm{min}$. The fractions were analyzed by using Orbitrap Fusion mass spectrometer at a resolution of 120,000 at $\mathrm{m} / z=200$. The compound peaks were determined according to the monoisotopic peak of compounds with an error of $10 \mathrm{ppm}$.

\section{Generation of PMO animal models and BSNXD administration}

The animal experiments were approved by the experimental animal ethics committee of Fudan University and were performed according to the Principles of Laboratory Animal Care (NIH publication number 85-23, revised 1985). We evaluated 95 female BALB/c mice, 8 weeks old, with a body mass between $20 \mathrm{~g}$ and $30 \mathrm{~g}$, which were purchased from the Laboratory Animal Facility of Chinese Academy of Sciences (Shanghai, People's Republic of China). Eighty mice underwent bilateral oophorectomy. A sham group (15 mice) underwent the surgical procedure without ovariectomy. After ovariectomy, the mice were then randomly divided into five groups (OVX, OVX + BSNXD low dose, OVX + BSNXD mid dose, $\mathrm{OVX}+\mathrm{BSNXD}$ high dose, and OVX $+\mathrm{E} 2 ; \mathrm{n}=16$ per group). During the experimental period, five mice died during the administration of anesthesia, but there were no deaths from other causes. The mice that died were excluded from the analysis.

The OVX control group was treated with saline $(n=15)$, and the OVX + BSNXD high-dose, OVX + BSNXD middose, and OVX + BSNXD low-dose group mice were treated twice daily with $0.5 \mathrm{~mL}$ of evaporated BSNXD extract (total raw herbs $2 \mathrm{~g} / \mathrm{mL}, 1 \mathrm{~g} / \mathrm{mL}$, and $0.5 \mathrm{~g} / \mathrm{mL}$, w $/ \mathrm{v}$ ) by oral administration (Table 1) at dosages that were 18-fold, 9-fold, and 4.5-fold the human adult dose, based on an established formula for human-mice drug conversion $(n=15)$. The $\mathrm{OVX}+\mathrm{E} 2$ group received estrogen (17- $\beta$-estradiol) treatment $(100 \mu \mathrm{g} / \mathrm{kg} /$ day orally, $\mathrm{n}=15) .{ }^{15-18}$ At 12 weeks after the treatment, all mice were weighed and then were sacrificed after the last treatment to harvest blood samples and tissues for further investigation. Successful ovariectomy was confirmed in all OVX animals by observation of the lack of ovarian tissue and atrophied uterine horns.

\section{BSNXD plus aromatase inhibitor letrozole treatment experiments}

Another in vivo experiment was performed to determine whether the BSNXD could act through an estrogen derivative or metabolite. We treated OVX mice with saline or mid-dose BSNXD (total raw herbs $1 \mathrm{~g} / \mathrm{mL}$, w/v) by oral administration, and then, they were divided into four treatment groups, as follows: mice that received the carrier solvent and $0.04 \mu \mathrm{g} / \mathrm{day}$, $0.2 \mu \mathrm{g} /$ day, and $2 \mu \mathrm{g}$ /day letrozole injection for 3 months ( $\mathrm{N}=13$, all groups). Letrozole was dissolved in $0.1 \mathrm{~mL}$ of $0.3 \%$ hydroxyl propyl cellulose and given as subcutaneous injections. The letrozole doses were selected as previously described. ${ }^{19}$

\section{Bone mineral density analysis}

Dual-energy X-ray absorptiometry was performed using an animal PIXImus densitometer (Lunar, GE Corp., Fairfield, CT, USA) in isolated left femur and lumbar vertebras (L3-4) after dissection to determine the bone mineral density 
(BMD). A consistent region of interest (the distal $4 \mathrm{~mm}$ of femur) was selected to maintain uniformity between the samples in the analysis.

\section{Bone histomorphometric analysis}

All bone histomorphometric analyses were performed according to a previously described protocol..$^{20,21}$ Briefly, the left tibia was isolated from each mouse; later, their proximal ends were trimmed off and fixed in phosphate-buffered saline (PBS)-buffered 3.7\% formaldehyde for 18 hours at $4^{\circ} \mathrm{C}$. After 24-hour incubation in $70 \%$ ethanol, the undecalcified left proximal tibiae were dehydrated in ascending alcohol concentrations, cleared in xylene, and embedded in methyl methacrylate; later, they were sectioned $(5 \mu \mathrm{m})$. These sections were stained with toluidine blue, and the von Kossa procedure was performed as indicated in a standard protocol. ${ }^{22}$

The parameters of static and dynamic histomorphometry were quantified on undecalcified proximal tibia sections $(5 \mu \mathrm{m})$. To evaluate the number of osteoclasts (OCs), decalcified proximal tibiae were embedded in paraffin. Serial sections were prepared from paraffin blocks ( $6 \mu \mathrm{m}$ thickness) and were stained for TRAP activity. The bone volume, OB, OC numbers, bone surface (BS), bone volume/tissue volume (\%), OB surface/BS (\%), osteoid surface/BS (\%), OC surface/BS (\%), OC number/bone perimeter $(1 / \mathrm{mm})$, and eroded surface/BS (\%) were measured according to standardized protocols using the Osteo-Measure Histomorphometry System (Osteometrics, Atlanta, GA, USA). All of these parameters are in accordance with the histomorphometric nomenclature and definition of the American Society of Bone Mineral Research. ${ }^{23}$

\section{Calcein labeling}

To label the active bone formation sites in the mice, we used double labeling, with calcein as a marker. ${ }^{24}$ First, $2.5 \mathrm{mg} / \mathrm{mL}$ calcein was prepared in a $2 \%$ solution of sodium bicarbonate. The mice were weighed and injected twice, intraperitoneally, with calcein at a dose of $25 \mathrm{mg} / \mathrm{kg}$ body weight at 5 -day intervals. The mice were sacrificed at 2 days after the second injection.

Calcein double labeling was confirmed by fluorescence microscope measurements to determine the mineral apposition rate (MAR) and bone formation rate (BFR), which were evaluated on two nonconsecutive sections for each animal. The double calcein green labels were measured on bone trabeculae using fluorescence microscopy (Olympus BX-60, Tokyo, Japan) with an excitation wavelength of $485 \mathrm{~nm}$ and emission wavelength of $510 \mathrm{~nm}^{25}$ The mineralizing surface/BS (\%), MAR $(\mu \mathrm{m} / \mathrm{d})$, and BFR $\left(\mu \mathrm{m}^{3} / \mu \mathrm{m}^{2} /\right.$ year $)$ were measured according to standardized protocols using the
Osteo-Measure Histomorphometry System (Osteometrics, Decatur, GA, USA). All of these parameters are in accordance with the histomorphometric nomenclature and definition of the American Society of Bone Mineral Research. ${ }^{23}$

\section{Drug-derived serum preparation and measurement of E2 concentration}

At the end of experiment, mice were anesthetized and sacrificed. A blood sample was quickly obtained by cardiac puncture. Blood volumes of up to $1 \mathrm{~mL}$ have frequently been obtained from mice with this method. Serum samples were prepared by centrifugation. The serum samples were inactivated at $56^{\circ} \mathrm{C}$ for 30 minutes and filtrated with a $0.2 \mu \mathrm{m}$ filtrator; they were then stored at $-20^{\circ} \mathrm{C}$ for determination of the $\mathrm{E} 2$ concentrations. Additionally, the E2 concentrations in serum samples were measured using the E2 EIA kit according to the manufacturer's protocol.

\section{E2 EIA and aromatase activity analysis in site}

After 3 months of treatment, all the mice were killed; the femur and the tibia were removed at time of necropsy. As previously described, ${ }^{15} 0.5 \mathrm{~g}$ femur tissues were homogenized in $4 \mathrm{~mL}$ of PBS and centrifuged $\left(3,500 \mathrm{rpm}, 4^{\circ} \mathrm{C}\right.$ for 20 minutes). Then, we collected the supernatants aliquoted individually, and stored them at $-20^{\circ} \mathrm{C}$ until E2 assay.

The tibia fragments were used to detect P450arom activity (in vitro conversion of testosterone to E2). As previously described, ${ }^{15} 100 \mathrm{mg}$ tibia fragments were placed in the 24-well tissue culture dish with $1 \mathrm{~mL}$ of 1640 medium. Afterward, they were incubated in the presence or absence of testosterone $(100 \mathrm{ng} / \mathrm{mL})$ for 24 hours at $20^{\circ} \mathrm{C}$ in a humidified incubator. When the incubation was completed, the media were collected and frozen at $-20^{\circ} \mathrm{C}$ until E2 assay.

E2 concentrations in the supernatants of bone homogenate samples and the incubated media were measured using the E2 EIA kit according to the manufacturer's protocol.

\section{Uterus histomorphometry}

After euthanasia, the uteruses were removed from the mice, and the wet weights were measured; macroscopic examination followed. Samples of uterine tissues were fixed in PBS-buffered 4\% formaldehyde for 12 hours, air-dried, and embedded in paraffin. Sections ( $4 \mu \mathrm{m}$ thick) were cut, mounted on slides, deparaffinized with a graded series of xylene, and rehydrated in a descending graded alcohol series. Sections ( $4 \mu \mathrm{m}$ thick) were stained with hematoxylin and eosin. The slides were then scanned and analyzed with the Image-Pro Plus (Media Cybernetics, Bethesda, MD, USA). 


\section{Statistical analysis}

All values are expressed as the mean \pm standard deviation. The difference between experimental groups was analyzed with analysis of variance and Kruskal-Wallis tests, and $P<0.05$ was considered significant. Data were analyzed with the SPSS database.

\section{Results}

\section{BSNXD administration ameliorated the BMD of OVX mice}

A significant decrease in the femur and vertebra BMD was observed in the OVX mice compared to the sham mice, and the OVX animals that were treated with mid-dose and high-dose BSNXD or E2 treatment had significantly higher femur $(P<0.01$, Figure 2A) and vertebra BMD $(P<0.01$, Figure $2 \mathrm{~B})$, compared to the OVX group that returned to the sham (normal) levels. No significant difference was observed between low-dose BSNXD and OVX $(P>0.05$, Figure 2A and B).

\section{BSNXD administration improved the bone phenotype of OVX mice}

As expected, ovariectomy significantly increased the bone turnover with resorption exceeding formation, leading to loss of the bone microarchitecture compared to the sham group. Analysis of static bone histomorphometric parameters showed elevations in the OB surface/BS, osteoid surface/BS, mineralizing surface/BS, MAR, and BFR in OVX mice $(P<0.01$ or $P<0.05$, Figures 3B and 4B). Compared to OVX, 12-week treatment with mid-dose or high-dose BSNXD increased the bone volume/tissue volume, OB surface/BS, osteoid surface/BS, mineralizing surface/BS, and BFR (all $P<0.01$, Figures 3B and 4B), indicating further enhancement of osteoblastic recruitment. Neither low-dose BSNXD nor E2 treatment significantly affected the aforementioned dynamic bone histomorphometry parameters after the 12-week treatment compared to the OVX group $(P>0.05$, Figures 3B and 4B).

Static histomorphometry confirmed loss of bone microarchitecture for the OVX mice compared to sham mice. Specifically, ovariectomy significantly increased the OC surface/ $\mathrm{BS}$, OC number/bone perimeter, and eroded surface/BS compared to the sham group (all $P<0.01$, Figure 3B). After 12 weeks of treatment, mid-dose and high-dose BSNXD and E2 significantly decreased the OC surface/BS, OC number/ bone perimeter, and eroded surface/BS compared to the OVX group (all $P<0.01$, Figure 3B). Histomorphometric analysis showed that low-dose BSNXD treatment did not significantly change the aforementioned OC parameters compared to the OVX group $(P>0.05$, Figure $3 \mathrm{~B})$.

\section{Ameliorating effects of BSNXD on OVX- induced bone loss could not be abolished by the aromatase inhibitor letrozole}

The in vivo experiment (BSNXD plus letrozole treatment experiments) showed that letrozole $(0.04 \mu \mathrm{g} / \mathrm{day}, 0.2 \mu \mathrm{g} /$ day, and $2 \mu \mathrm{g} /$ day) decreased the E2 concentration in sham mice $(P<0.05$, Figure 5A). The serum E2 concentration of
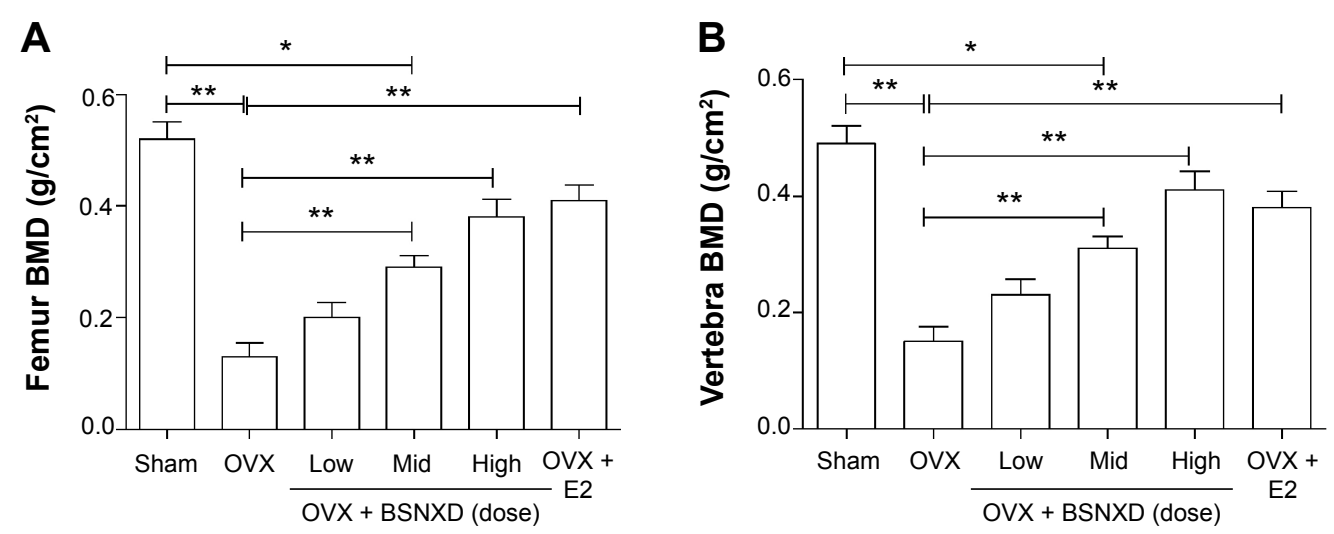

Figure 2 Effect of the traditional Chinese herbal formula BSNXD on BMD of OVX mice.

Notes: The OVX mice were randomly divided into the following groups: the OVX control group that received saline treatment ( $\mathrm{n}=15$ ); the OVX + BSNXD high-dose group; OVX + BSNXD mid-dose group; and OVX + BSNXD low-dose group mice that were treated with $0.5 \mathrm{~mL}$ of evaporated BSNXD extract, twice daily (total raw herbs $2 \mathrm{~g} / \mathrm{mL}, 1 \mathrm{~g} / \mathrm{mL}$, and $0.5 \mathrm{~g} / \mathrm{mL}, \mathrm{w} / \mathrm{v}$ ) by oral administration $(\mathrm{n}=15)$; and the OVX + E2 group that was treated with E2 treatment (I00 $\mu \mathrm{g} / \mathrm{kg} /$ day orally, $\mathrm{n}=15)$. After $12 \mathrm{weeks}$ of treatment, all mice were sacrificed after the final treatment, and bone tissues were harvested for further investigation. Dual-energy $X$-ray absorptiometry was performed to determine the BMD. The data were analyzed with an animal PIXImus densitometer; analysis results of the left femur $(\mathbf{A})$ and lumbar vertebras (B) in the different groups are expressed as the mean $\pm S D$. $* P<0.05$ and $* * P<0.01$.

Abbreviations: BSNXD, Bu-Shen-Ning-Xin Decoction; BMD, bone mineral density; OVX, ovariectomized; E2, estradiol; SD, standard deviation. 

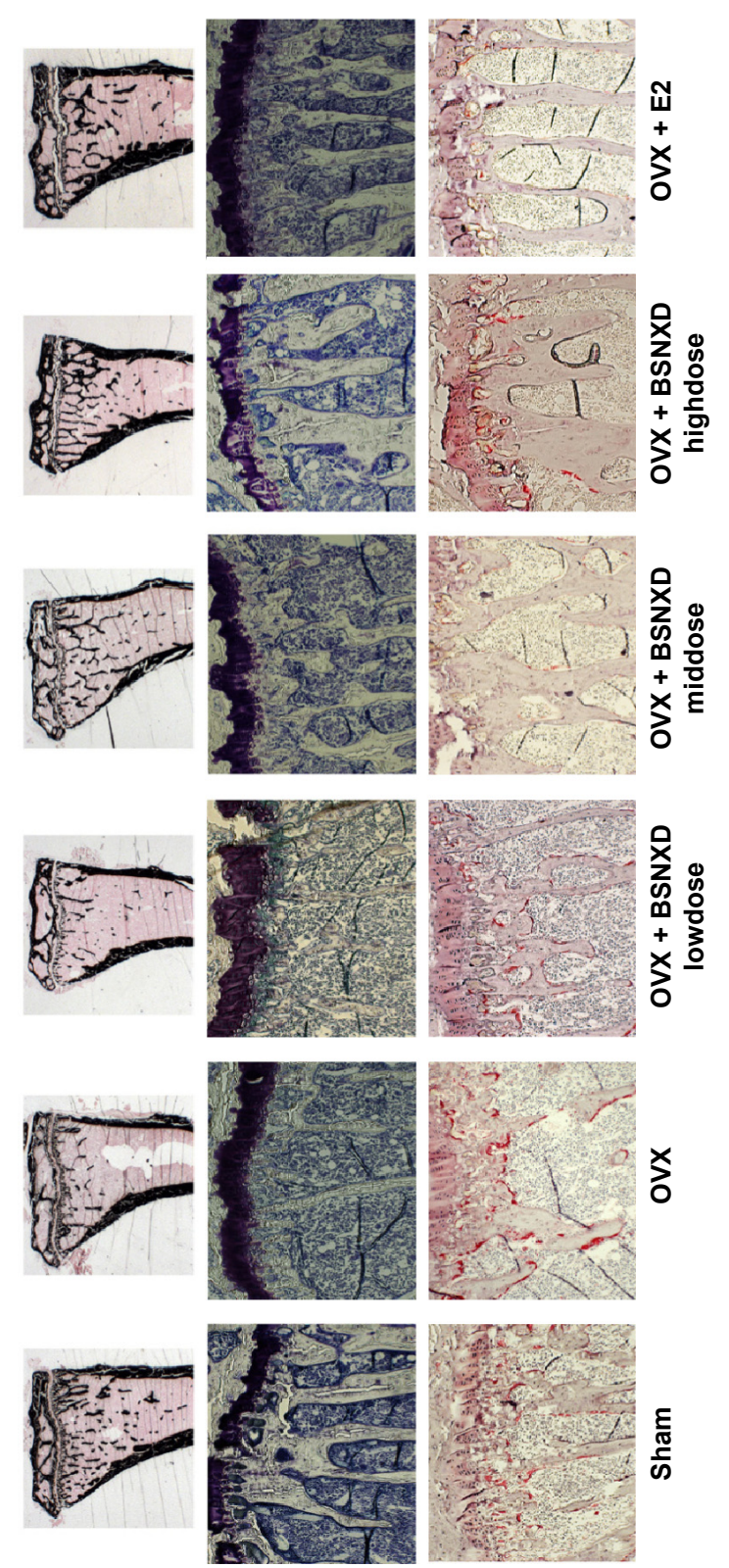

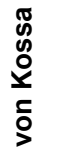

$\frac{0}{0}$
$\frac{0}{0}$
음
$\frac{0}{3}$
음

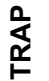

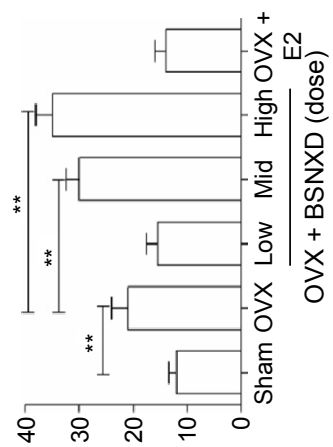

(\%) әэенuns әuоq /əöjuns p!oəzso

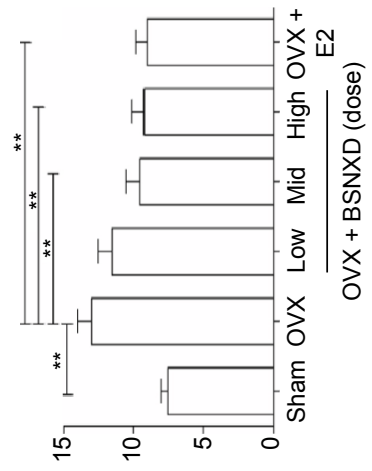

(\%) әэенuns әuоq /әэедиns рәрод

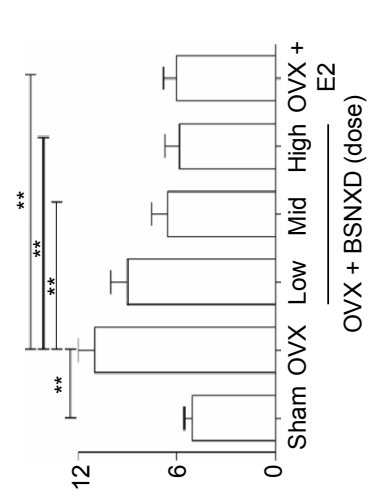

(mu/L) גәңәш!ıәd әиоq

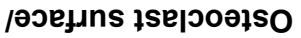

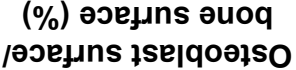

$\stackrel{x}{3}$

$\frac{\varepsilon}{\frac{5}{\omega}}$

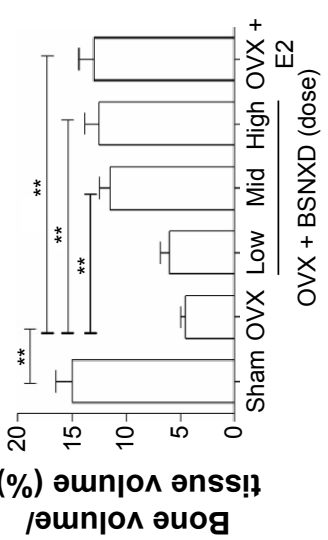

$\boldsymbol{m}$ 
A

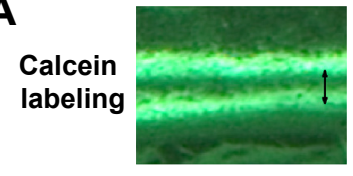

Sham

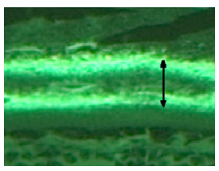

ovx

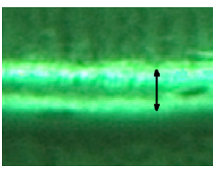

OVX + BSNXD

lowdose

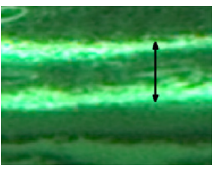

OVX + BSNXD middose

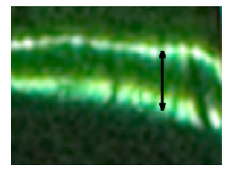

OVX + BSNXD highdose

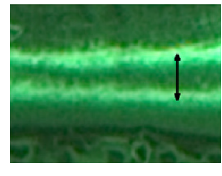

OVX + E2

B
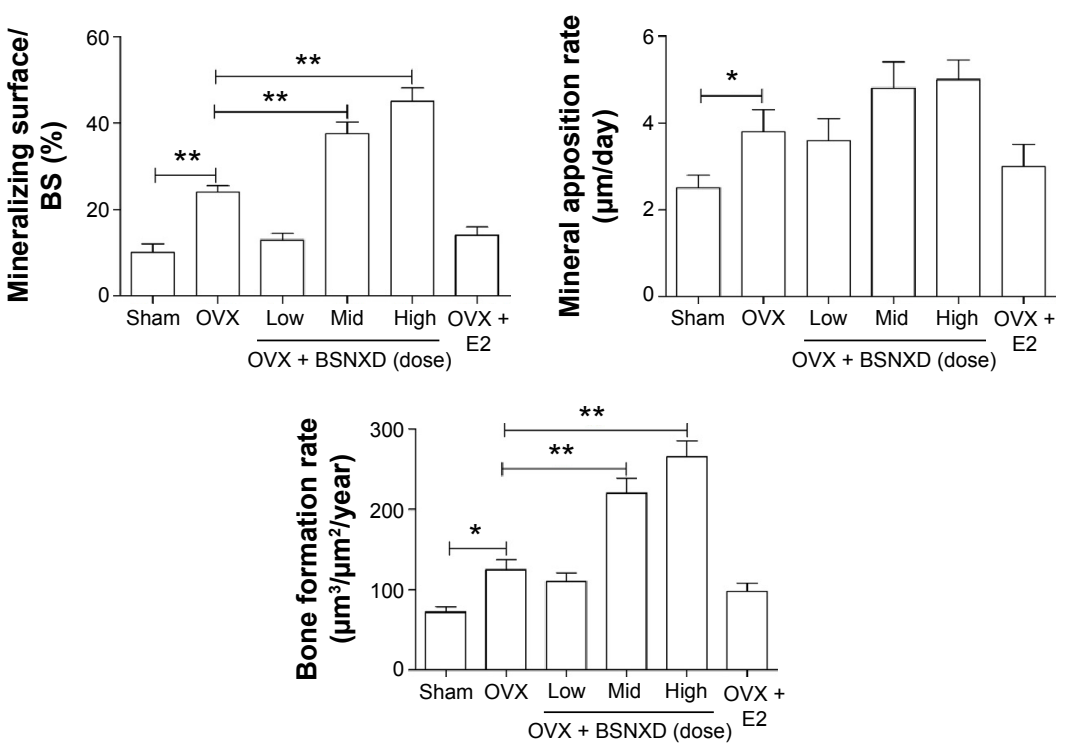

Figure 4 Dynamic bone histomorphometry of the proximal tibia.

Notes: (A) Calcein double labels were measured on bone trabeculae by fluorescence microscope measurements with an excitation wavelength of $485 \mathrm{~nm}$ and an emission wavelength of $510 \mathrm{~nm}$ for each group. The arrows represent the bone formation during the interval between the two injections of calcein. (B) To determine the mineralizing surface/BS, mineral apposition rate, and bone formation rate, calcein double labeling was analyzed with the Osteo-Measure Histomorphometry System. Data are expressed as the mean $\pm S D$. $* P<0.05$ and $* * P<0.01$.

Abbreviations: BS, bone surface; SD, standard deviation; OVX, ovariectomized; BSNXD, Bu-Shen-Ning-Xin Decoction; E2, estradiol.

OVX mice was significantly lower than that of the sham mice $(P<0.05$, Figure 5A). In the OVX mice, mid-dose BSNXD, administered alone or in combination with letrozole, did not significantly change the E2 concentration in serum $(P>0.05$, Figure 5A).

OVX mice had a lower femur BMD, vertebra BMD, and bone volume/tissue volume, and animals treated with letrozole $(0.04 \mu \mathrm{g} /$ day, $0.2 \mu \mathrm{g} /$ day, and $2 \mu \mathrm{g} /$ day $)$ had a similar bone phenotype ( $P>0.05$, Figure $5 \mathrm{~B}$ and $\mathrm{C})$. The mid-dose BSNXD-treated OVX mice had a higher femur BMD, vertebra BMD, and bone volume/tissue volume compared to the OVX group, whereas the letrozole-treated OVX mice that also received mid-dose BSNXD had similar parameters as the mid-dose BSNXD-treated OVX (Figure $5 \mathrm{~B}$ and $\mathrm{C}$ ). OVX also influenced the $\mathrm{OC}$ surface/BS and OC number/bone perimeter; the animals that received letrozole had a perimeter that was similar to the OVX group. The OC surface/BS and OC number/bone perimeter were decreased in the OVX group treated with mid-dose BSNXD compared to the OVX group. Letrozole did not have a significant effect on the $\mathrm{OC}$ surface/BS and OC number/bone perimeter in the BSNXD-treated OVX group ( $P>0.05$, Figure 5D).

\section{BSNXD treatment increased the aromatase activity and E2 concentration in bone}

In femurs, compared to the sham mice, the concentration of E2 after ovariectomy had significantly decreased $(P<0.01$, Figure 6A), and E2 administration significantly increased E2 concentration $(P<0.01$, Figure $6 \mathrm{~A})$; interestingly, unlike the serum level, treatment with BSNXD increased E2 concentration in site as well $(P<0.01$, Figure 6A).

To determine aromatase activity in site, E2 production in vitro was assayed in tibia fragments obtained from each group to detect the P450arom enzyme activity. Low levels of E2 were present in each group when tibia fragments were incubated without testosterone (Figure 6B). Meanwhile, when tibia fragment was incubated with testosterone, E2 production in both of the groups increased (Figure 6B). The difference in E2 level with or without testosterone could 


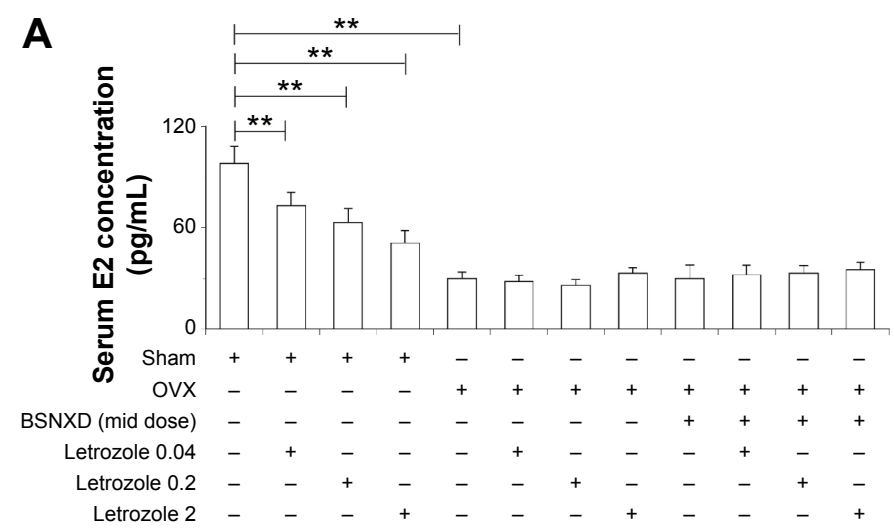

B
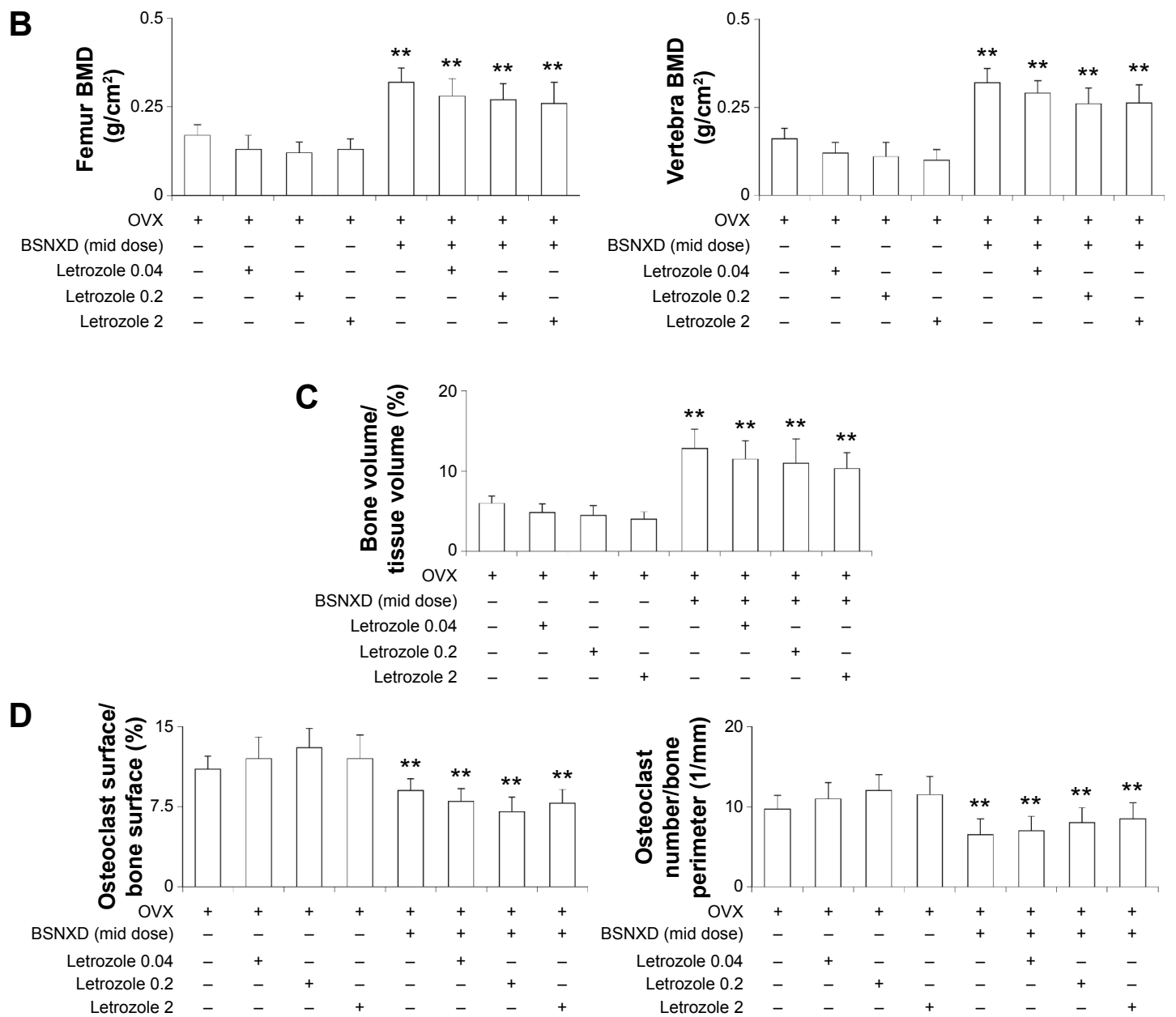

Figure 5 The ameliorating effects of BSNXD on the osteoporotic phenotype of OVX mice could not be abolished by aromatase inhibitor letrozole.

Notes: OVX mice were treated with saline or mid-dose BSNXD (total raw herbs $1 \mathrm{~g} / \mathrm{mL}$, w/v) by oral administration, and were then divided into the following four treatment groups: mice that were treated with the carrier solvent and $0.04 \mu \mathrm{g} / \mathrm{day}, 0.2 \mu \mathrm{g} / \mathrm{day}$, and $2 \mu \mathrm{g} / \mathrm{day}$ letrozole injection for 3 months ( $\mathrm{N}=13$, all groups). After 12 weeks of treatment, all mice were sacrificed, and bone tissues were harvested for further investigation. (A) The E2 concentrations in sera were measured with an enzyme immunoassay kit. (B) The BMD analysis of the left femur and lumbar vertebras in different groups. (C) The bone volume/tissue volume. (D) The osteoclast surface/bone surface and osteoclast number/bone perimeter. Data are expressed as the mean $\pm S D$. $* * P<0.01$.

Abbreviations: BSNXD, Bu-Shen-Ning-Xin Decoction; OVX, ovariectomized; E2, estradiol; SD, standard deviation; BMD, bone mineral density.

be due to testosterone being aromatized; it could reflect aromatase activity in each group. Figure 5C shows that the difference in E2 production in OVX mice decreased significantly compared to that in sham mice $(P<0.05$, Figure $6 \mathrm{C})$. The E2 treatment increased E2 production by tibia tissue fragments $(P<0.01$, Figure $6 \mathrm{C})$, and the BSNXD treatment significantly increased $\mathrm{E} 2$ production $(P<0.01$, Figure $6 \mathrm{C})$. It is suggested that BSNXD could significantly increase the aromatase activity, contributing to increase in estrogen concentration in bone but not in serum. 
A

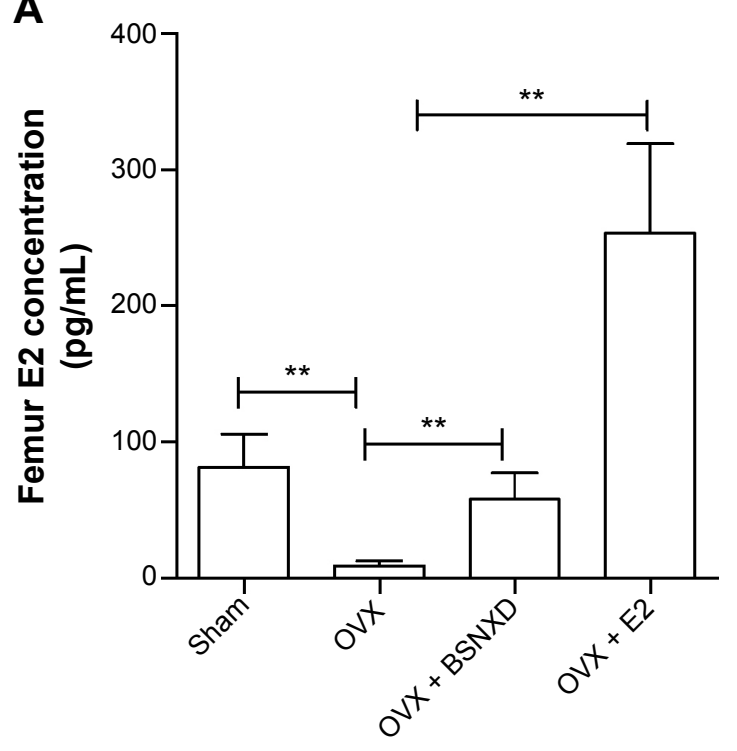

B

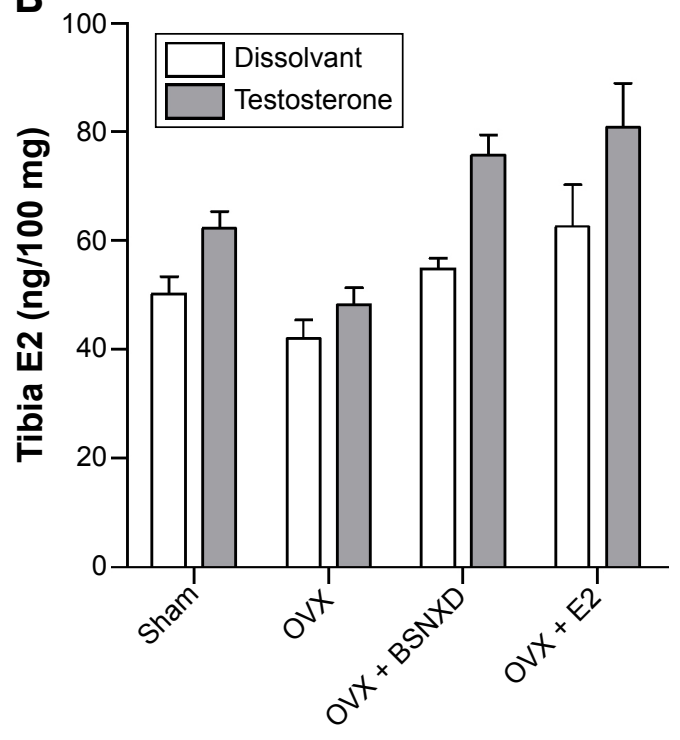

C

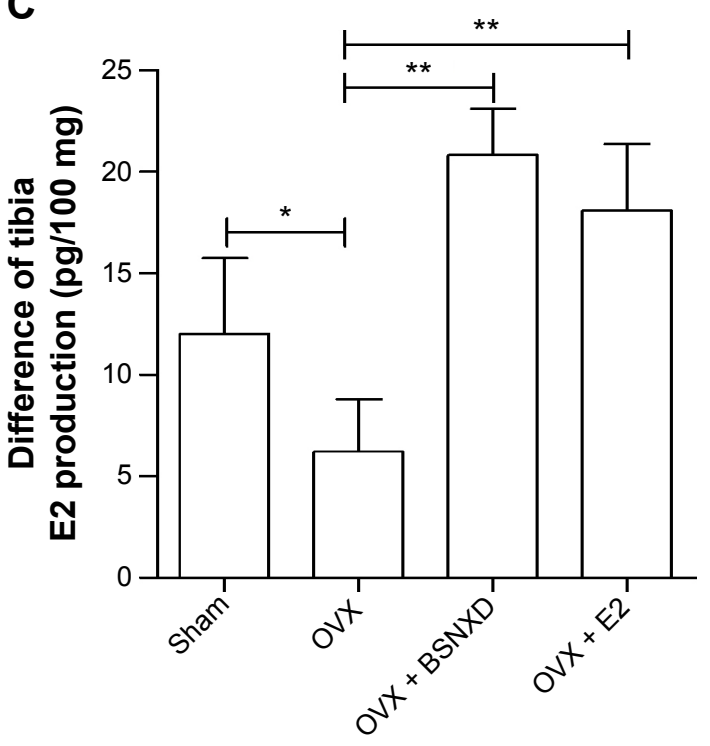

Figure 6 Effects of administrations of BSNXD or E2 on E2 concentrations in the femur tissue homogenate, and modulation of these administrations on aromatase activity in the tibia.

Notes: (A) E2 levels in the femur tissue homogenate of BSNXD or E2-treated, control OVX, and sham mice were assayed by EIA. In vitro production of E2 in the tibia of BSNXD or E2-treated, control OVX, and sham mice was assayed to evaluate the profile of P450arom activity. Tibia (I00 mg) preparations were incubated in the absence or presence of testosterone ( $100 \mathrm{ng} / \mathrm{mL})$ for 24 hours. (B) E2 level in tibia tissue media of each group with or without testosterone was assayed by EIA. The difference in E2 level with or without testosterone could be due to the testosterone being aromatized or it could reflect aromatase activity in each group. (C) The difference in E2 production due to testosterone aromatized in tibia. Data are expressed as mean $\pm S D(n=5)$. $* P<0.05$ and $* * P<0.01$.

Abbreviations: BSNXD, Bu-Shen-Ning-Xin Decoction; E2, estradiol; OVX, ovariectomized; ElA, enzyme immunoassay; SD, standard deviation.

\section{BSNXD did not stimulate the uterus}

The uterine columnar epithelium atrophied, uterine gland number reduced, and mitosis in the epithelium was reduced in the OVX mice (data not shown). The success of ovariectomy was confirmed by the uterine weight, and the average wet weight of the uterus and relative uterus wet weight of OVX mice were significantly lower than that of the ovaryintact mice $(P<0.01)$. The wet weight of the uterus, relative uterus wet weight, and endometrial glands were not affected by BSNXD treatment (low dose, mid dose, or high dose), while the uterus was enlarged and wet weight of the uterus and relative uterus wet weight were significantly increased in the E2-treated group compared to the OVX group $(P<0.01$, Figure 7).

\section{Discussion}

After ovariectomy, there is a sudden and dramatic decrease in the estrogen production from the arrest of ovarian function. 

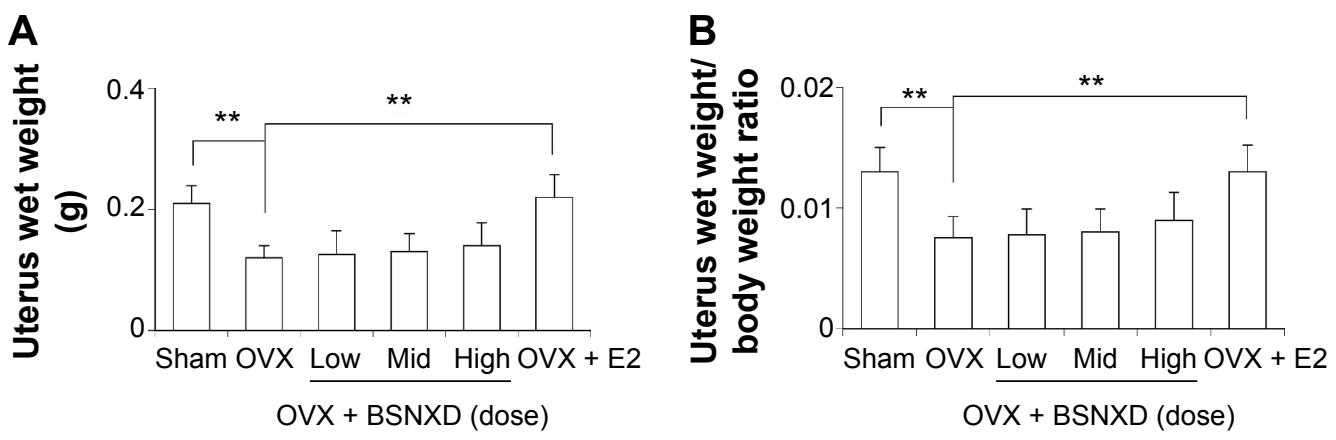

Figure 7 Effects of administration of BSNXD (low, mid, or high dose) and E2 on the uterus wet weight.

Notes: Mice were necropsied after 12 weeks of treatment, and the wet weights of uterus were determined. (A and $\mathbf{B})$ The wet weight of the uterus and relative weight of uterus, respectively. BSNXD (low, mid, or high dose) treatments caused no significant change in the uterus wet weight, while E2 administration caused a significant increase. Data are expressed as the mean $\pm S D(n=15)$. $* * P<0.01$.

Abbreviations: BSNXD, Bu-Shen-Ning-Xin Decoction; E2, estradiol; SD, standard deviation; OVX, ovariectomized.

The loss of sex steroids leads to an increase in bone resorption from the increased OC formation and lifespan. The net bone loss caused by OVX is limited by an increase in the bone formation from stimulated OB formation. The stimulatory effect of OVX on osteoblastogenesis is relevant to osteoclastogenesis because one of the consequences of E2 deprivation is the formation of $\mathrm{OB}$ with increased osteoclastogenic activity. Therefore, OVX increases bone remodeling because both osteoclastogenesis and osteoblastogenesis are upregulated. ${ }^{26-28}$ This increased bone turnover shifts the bone homeostasis toward bone resorption, resulting in rapid trabecular bone loss and an increased risk of skeletal fracture. ${ }^{29}$

In the present study, we found that mid-dose and highdose BSNXD and E2 administration inhibited the bone loss caused by OVX. We observed improvements in BMD caused by mid- or high-dose BSNXD that were somewhat similar to the change observed in E2 treatment. Moreover, our bone morphometric analysis confirmed that mid-dose and highdose BSNXD and E2 could ameliorate the bone phenotype of OVX mice as well as downregulate the OC parameters. Furthermore, mid- or high-dose BSNXD could increase the OB parameters and BFR. However, E2 increases the bone mass after ovariectomy just mainly via weakening the OC parameters without affecting OB parameters as well as BFR. These results suggest that BSNXD plays an important role in osteoclastogenesis and OB differentiation. Previously, we have found that BSNXD pharmacological serum both promoted the proliferation and inhibited the apoptosis of murine OBs through activating MAPK signaling pathways via phosphorylation of ERK $1 / 2,{ }^{9}$ which is in accordance with our current results. However, BSNXD's effect on osteoclastogenesis is still uncertain.

Many TCMs exert their antiosteoporotic effects by acting with their estrogenic activity. Thus, we detected the serum
E2 concentration to identify the underlying mechanism of BSNXD suppressing the OC parameters. Our results showed that, no matter with or without the aromatase inhibitor letrozole, the estrogen level in the BSNXD-derived serum was comparable to the control serum. Furthermore, BSNXD's ameliorating effect on osteoporotic phenotype of OVX mice could not be abolished by letrozole. Our data indicate that the systemic estrogen derivative or metabolite is not involved in the beneficial effect of BSNXD on the bone phenotype.

Not only the circulating serum estrogen but also the local production of estrogen plays the key role in bone homeostasis in postmenopausal women. So, we detected the local estrogen level in bone. In Figure 5C, the difference in E2 level with or without testosterone reflects aromatase activity in each group, which is the ability to convert testosterone to E2 in vitro. It showed that the aromatase activity in OVX mice decreased significantly compared to that in sham mice. Not only the E2 treatment but also the BSNXD treatment increased the aromatase activity. It is suggested that BSNXD significantly increases the aromatase activity, contributing to an increase in estrogen concentration in bone but not in serum.

There are eight crude herbs in this formula (Table 1), and each of the crude herbs consists of many kinds of chemicals such as iridoids, phenylethanoid glucosides, flavonoids, lignans, and saponins. (Table 1 and Figure 1) Acteoside in Drying Rehmannia Root suppressed RANKLmediated osteoclastogenesis by inhibiting c-Fos induction and NF- $\kappa$ B pathway and attenuating ROS production, ${ }^{30}$ and the icariin in Shorthorned Epimedium Herb inhibited the osteoclastogenesis in vitro, ${ }^{31}$ which are in accordance with our results in this study. However, the flavonoids isolated from Chinese Dodder Seed increased the level of estrogen in peripheral blood of mice; ${ }^{32}$ it is inconsistent with our results. May be during the process of preparation of the extract of the 
BSNXD, the structures of the flavonoids were transformed, or some unknown substances decreasing the estrogen level were generated.

Besides elevating estrogen level, many TCMs exert their antiosteoporotic effects by acting with their SERM-like activity; for example, icariin, isolated from Shorthorned Epimedium Herb, induces OB proliferation, differentiation, and mineralization through estrogen receptor-mediated ERK and JNK signal activation. ${ }^{33}$ In a previous study, we found that BSNXD elevated serum level of dehydroepiandrosterone (DHEA), ${ }^{34}$ which was a pre-hormone and could be transformed in peripheral tissues to more potent androgen or estrogen. ${ }^{35}$ Many studies suggested a beneficial effect of DHEA administration on preventing trabecular BMD loss in women with estrogen deficiency. ${ }^{36,37}$ In in vitro analysis, primary human OBs showed aromatase activity converting DHEA to estrogen. ${ }^{36}$ But the identification of DHEA receptors in the liver, kidney, and testes of rats suggests that DHEA has specific physiologic actions of its own. ${ }^{35,38-40}$ A previous study also showed that DHEA inhibited osteoclastogenesis via estrogen receptor $\alpha$-dependent pathway rather than estrogen receptor $\beta$ - or androgen receptor-dependent pathway. ${ }^{34}$ In fact, we had examined the estrogenic or SERM-like activity of BSNXD drug-derived serum on osteoclastogenesis as well. Our results showed that BSNXD inhibited osteoclastogenesis by abrogation of the RANKL-induced NFATc1 and NF- $\kappa$ B signaling pathways via selective estrogen receptor $\alpha{ }^{41}$

On the other hand, we observed that after 12 weeks following ovariectomy, the uterus of mice got atrophied significantly compared to that of the sham mice due to sexual hormone deprivation. The uterine columnar epithelium atrophied, uterine gland number reduced, and mitosis in the epithelium was reduced. The other OVX mice were treated with serial dose of BSNXD or E2 for 12 weeks. Then, we found that uterus of low-, mid-, and high-dose BSNXD-treated mice also got atrophied and the degree was modest compared to the OVX group mice. That is to say, the BSNXD did not stimulate the uterus, which might account for that BSNXD has no estrogenic or SERM-like activity. However, E2 had the proliferative effect on the endometrium and uterus, and increased the net weight of uterus as well as the relative weight (uterus wet weight/body weight ratio). Although mid- and high-dose BSNXD and E2 enhanced BMD, the differential characteristics of BSNXD and E2 reflected their different actions on the bone and uterus. The benefit-to-risk ratio may be more favorable for BSNXD therapy than for E2 therapy. It is possible that the relatively long duration of BSNXD therapy could be safely used to prevent and mitigate PMO.

Although we identified the efficacy and security of BSNXD to ameliorate bone loss in PMO, the specific mechanism is still uncertain. Further studies are needed to determine the SERM-like activity of BSNXD and whether BSNXD modulates bone metabolism via regulating osteoblastogenesis or osteoclastogenesis.

\section{Conclusion}

This study revealed that BSNXD could ameliorate the OVX-induced bone loss without affecting the peripheral blood estrogen concentration and uterus, suggesting that this cocktail therapy is a good option for treating PMO.

\section{Acknowledgments}

This work was supported by the National Natural Science Foundation of China (number 31571196; L Wang), the Science and Technology Commission of Shanghai Municipality 2015 YIXUEYINGDAO (project number 15401932200; L Wang), the FY2008 JSPS Postdoctoral Fellowship for Foreign Researchers (P08471; L Wang), the National Natural Science Foundation of China (number 30801502; L Wang), the Shanghai Pujiang Program (number 11PJ1401900; L Wang), the National Natural Science Foundation of China (number 81401171; X-M Qiu), and the Program for Outstanding Medical Academic Leader (D-J Li).

\section{Disclosure}

The authors report no conflicts of interest in this work.

\section{References}

1. Rossouw JE, Anderson GL, Prentice RL, et al; Writing Group for the Women's Health Initiative Investigators. Risks and benefits of estrogen plus progestin in healthy postmenopausal women: principal results from the Women's Health Initiative randomized controlled trial. JAMA. 2002;288(3):321-333.

2. Pinkerton JV, Stovall DW. Reproductive aging, menopause, and health outcomes. Ann N Y Acad Sci. 2010;1204:169-178.

3. Silverman S, Christiansen C. Individualizing osteoporosis therapy. Osteoporos Int. 2012;23(3):797-809.

4. Body JJ. How to manage postmenopausal osteoporosis? Acta Clin Belg. 2011;66(6):443-447.

5. Efferth T, Li PC, Konkimalla VS, Kaina B. From traditional Chinese medicine to rational cancer therapy. Trends Mol Med. 2007;13(8): 353-361.

6. Wang L, Zhou GB, Liu P, et al. Dissection of mechanisms of Chinese medicinal formula Realgar-Indigo naturalis as an effective treatment for promyelocytic leukemia. Proc Natl Acad Sci U S A. 2008;105(12): 4826-4831.

7. Chow MS, Huang Y. Utilizing Chinese medicines to improve cancer therapy - fiction or reality? Curr Drug Discov Technol. 2010;7(1):1. 
8. Wang L, Qiu XM, Hao Q, Li DJ. Anti-inflammatory effects of a Chinese herbal medicine in atherosclerosis via estrogen receptor beta mediating nitric oxide production and NF-kappaB suppression in endothelial cells. Cell Death Dis. 2013;4:e551.

9. Wang Y, Cui K, Zhao H, Li D, Wang W, Zhu Y. Bushen Ningxin Decoction pharmacological serum promotes the proliferation and suppresses the apoptosis of murine osteoblasts through MAPK pathway. J Ethnopharmacol. 2009;122(2):221-226.

10. Goto T, Hagiwara K, Shirai N, Yoshida K, Hagiwara H. Apigenin inhibits osteoblastogenesis and osteoclastogenesis and prevents bone loss in ovariectomized mice. Cytotechnology. 2015;67(2):357-365.

11. Messer JG, Hopkins RG, Kipp DE. Quercetin metabolites up-regulate the antioxidant response in osteoblasts isolated from fetal rat calvaria. $J$ Cell Biochem. 2015;116(9):1857-1866.

12. Zhu S, Chen K, Lan Y, Zhang N, Jiang R, Hu J. Alendronate protects against articular cartilage erosion by inhibiting subchondral bone loss in ovariectomized rats. Bone. 2013;53(2):340-349.

13. Hsiao HB, Lin H, Wu JB, Lin WC. Kinsenoside prevents ovariectomyinduced bone loss and suppresses osteoclastogenesis by regulating classical NF-kappaB pathways. Osteoporos Int. 2012;24(5):1663-1676.

14. P.R.China Tspco, editor. Pharmacopoeia of the People's Republic of China. Beijing: Chemical Industry Press; 2005.

15. Wang L, Wang YD, Wang WJ, Li DJ. Differential regulation of dehydroepiandrosterone and estrogen on bone and uterus in ovariectomized mice. Osteoporos Int. 2009;20(1):79-92.

16. Wang L, Wang YD, Wang WJ, Zhu Y, Li DJ. Dehydroepiandrosterone improves murine osteoblast growth and bone tissue morphometry via mitogen-activated protein kinase signaling pathway independent of either androgen receptor or estrogen receptor. J Mol Endocrinol. 2007; 38(4):467-479.

17. Kohama SG, Anderson CP, Osterburg HH, May PC, Finch CE. Oral administration of estradiol to young $\mathrm{C} 57 \mathrm{BL} / 6 \mathrm{~J}$ mice induces age-like neuroendocrine dysfunctions in the regulation of estrous cycles. Biol Reprod. 1989;41(2):227-232.

18. Tyagi AM, Srivastava K, Kureel J, et al. Premature T cell senescence in Ovx mice is inhibited by repletion of estrogen and medicarpin: a possible mechanism for alleviating bone loss. Osteoporos Int. 2012;23(3): 1151-1161.

19. Li F, Chow S, Cheung WH, Chan FL, Chen S, Leung LK. The citrus flavonone hesperetin prevents letrozole-induced bone loss in a mouse model of breast cancer. J Nutr Biochem. 2013;24(6):1112-1116.

20. Abdallah BM, Ditzel N, Mahmood A, et al. DLK1 is a novel regulator of bone mass that mediates estrogen deficiency-induced bone loss in mice. J Bone Miner Res. 2011;26(7):1457-1471.

21. Huebner AK, Schinke T, Priemel M, et al. Calcitonin deficiency in mice progressively results in high bone turnover. J Bone Miner Res. 2006; 21(12):1924-1934.

22. Yang JY, Cho SW, An JH, et al. Osteoblast-targeted overexpression of TAZ increases bone mass in vivo. PLoS One. 2013;8(2):e56585.

23. Parfitt AM, Drezner MK, Glorieux FH, et al. Bone histomorphometry: standardization of nomenclature, symbols, and units. Report of the ASBMR Histomorphometry Nomenclature Committee.JBone Miner Res. 1987;2(6):595-610.

24. Zhou X, Pu D, Liu R, et al. The Fgfr2 mutation in mice retards mandible formation and reduces bone mass as in human Apert syndrome. Am J Med Genet A. 2013;161A(5):983-992.
25. Holmes C, Khan TS, Owen C, Ciliberti N, Grynpas MD, Stanford WL. Longitudinal analysis of mesenchymal progenitors and bone quality in the stem cell antigen-1-null osteoporotic mouse. J Bone Miner Res. 2007; 22(9):1373-1386.

26. Jilka RL, Takahashi K, Munshi M, Williams DC, Roberson PK, Manolagas SC. Loss of estrogen upregulates osteoblastogenesis in the murine bone marrow. Evidence for autonomy from factors released during bone resorption. J Clin Invest. 1998;101(9):1942-1950.

27. Jilka RL, Hangoc G, Girasole G, et al. Increased osteoclast development after estrogen loss: mediation by interleukin-6. Science. 1992;257(5066): 88-91.

28. Li JY, Tawfeek H, Bedi B, et al. Ovariectomy disregulates osteoblast and osteoclast formation through the T-cell receptor CD40 ligand. Proc Natl Acad Sci U S A. 2011;108(2):768-773

29. Manolagas SC, Kousteni S, Jilka RL. Sex steroids and bone. Recent Prog Horm Res. 2002;57:385-409.

30. Lee SY, Lee KS, Yi SH, Kook SH, Lee JC. Acteoside suppresses RANKL-mediated osteoclastogenesis by inhibiting c-Fos induction and NF-kappaB pathway and attenuating ROS production. PLoS One. 2013; 8(12): 80873

31. Cui J, Zhu M, Zhu S, Wang G, Xu Y, Geng D. Inhibitory effect of icariin on Ti-induced inflammatory osteoclastogenesis. J Surg Res. 2014; 192(2):447-453.

32. Luo KY, Yang DL, Xu M. Effects of total flavones from cuscuta chinensis on gonadal hormone in animal model of ovulation failure. Chin J Exp Tradit Med Formulae. 2013;19(13):258-260.

33. Song L, Zhao J, Zhang X, Li H, Zhou Y. Icariin induces osteoblast proliferation, differentiation and mineralization through estrogen receptor-mediated ERK and JNK signal activation. Eur J Pharmacol. 2013;714(1-3):15-22.

34. Gui Y, Qiu X, Xu Y, Li D, Wang L. Bu-Shen-Ning-Xin decoction suppresses osteoclastogenesis via increasing dehydroepiandrosterone to prevent postmenopausal osteoporosis. Biosci Trends. 2015;9(3):169-181.

35. Traish AM, Kang HP, Saad F, Guay AT. Dehydroepiandrosterone (DHEA) - a precursor steroid or an active hormone in human physiology. J Sex Med. 2011;8(11):2960-2982. [quiz 2983].

36. Nawata H, Tanaka S, Tanaka S, et al. Aromatase in bone cell: association with osteoporosis in postmenopausal women. J Steroid Biochem Mol Biol. 1995;53(1-6):165-174.

37. Clarke BL, Ebeling PR, Jones JD, et al. Predictors of bone mineral density in aging healthy men varies by skeletal site. Calcif Tissue Int. 2002;70(3):137-145.

38. Magyar Z, Bekesi G, Racz K, et al. Increased total scavenger capacity and decreased liver fat content in rats fed dehydroepiandrosterone and its sulphate on a high-fat diet. Gerontology. 2011;57(4):343-349.

39. Jahn MP, Gomes LF, Jacob MH, et al. The effect of dehydroepiandrosterone (DHEA) on renal function and metabolism in diabetic rats. Steroids. 2011;76(6):564-570.

40. Sah C, Aridogan IA, Izol V, Erdogan S, Doran S. Effects of long-term administration of the antiaging hormone dehydroepiandrosterone sulfate on rat prostates and testes as androgen-dependent organs. Korean J Urol. 2013;54(3):199-203.

41. Wang L, Qiu XM, Gui YY, Xu YP, Gober HJ, Li DJ. Bu-Shen-Ning-Xin decoction: inhibition of osteoclastogenesis by abrogation of the RAN KL-induced NFATc1 and NF-KB signaling pathways via selective estrogen receptor $\alpha$. Drug Des Devel Ther. 2015;9:3755-3766.

\section{Publish your work in this journal}

Drug Design, Development and Therapy is an international, peerreviewed open-access journal that spans the spectrum of drug design and development through to clinical applications. Clinical outcomes, patient safety, and programs for the development and effective, safe, and sustained use of medicines are a feature of the journal, which

\section{Dovepress}

has also been accepted for indexing on PubMed Central. The manuscript management system is completely online and includes a very quick and fair peer-review system, which is all easy to use. Visit http://www.dovepress.com/testimonials.php to read real quotes from published authors. 